instructions fail to affect retention independently of their effect upon learning. It should be instructive in this regard to compare mnemonic with control Ss on a recognition test of retention.

The findings on type of error, although only the most general of the comparisons were significant, showed perfect internal consistency in direction. They were also consistent with the subjective reports of professional mnemonists, who report that if they forget their image, or fail to make one, they are often unable to make a response. This result may be relevant to the finding of Montague, Adams, \& Kiess (1966) and Adams \& McIntyre (1967) that Ss who forget their natural language mediators perform worse than Ss who do not report making them.

The observed flattening of the serial position curve is consistent with the implied claims of the mnemonic instructions that the functional stimulus for the mnemonic $S$ is the previous item, and that the difficulty of a given item should depend on its associative relations with the previous item rather than on its position in the list. It would also be possible to see it as consistent with the view that a mnemonic device operates by inducing an artificial meaningfulness in the material, since meaningfulness leads to flattening of the serial position curve (Braun \& Heymann, 1958).

\section{REFERENCFS}

ADAMS, J. A., \& McINTYRE, J. S. Natural language mediation and all-or-none learning. Canadian Journal of Psychology, 1967, 21, 436-449.

BRAUN, H. W., \& HEYMANN, S. P. Meaningfulness of material, distribution of practice, and serial position curves. Journal of Experimental Psychology, 1958, 56, 146-150.

DELIN, P. S. The learning to criterion of a serial list with and without mnemonic instructions. Psychonomic Science, 1969, 16, 4, 169-170.

DELIN. P. S. Learning and retention of English words with successive approximations to a complex mnemonic instruction. Psychonomic Science, $1969,17,2,87-89$.

JENSEN, A. R. Is the serial position curve invariant? British Journal of Psychology, 1962, 53, $159-166$.

MONTAGUE, W. E., ADAMS, J. A., \& KIESS, H. $O$. lorgetting and natural language mediation. Journal of Experimental Psychology, 1966, 72, 829-833.

OLTON, R. M. The effect of a mnemonic upon the retention of paired associate verbal material Unpublished doctoral dissertation, University of California, Berkeley, 1966.

ROCK, I. The role of repetition in associative lcarning. American Joumal of Psychology, 1957, 70, 186-193.

SMITH, K., \& NOBLE, C. E. Effects of a mnemonic technique applied to verbal learning and memory. Perceptual \& Motor Skills, 1965 , 21. 123-134.
IHURSTONE, L. L. The relation between learning time and length of task. Psychological Review, $1930,37,44-53$.

WNLLACLE, W. H., TURNIR. S. H., \& PERKINS,
C. C. Preliminary studies of human information storage. D.A. Project No. 3-99-12-023. S.C. Project No. 1320. University of Pennsylvania, 1957.

\title{
Do children really prefer visual complexity?
}

CORINNE HUTT and PENNY L. MCGREW,
Human Development Research Unit,
University of Oxford, Oxford, England

Children, 5, 8, and 11 years of age, were given the choice of exposing for themselves simple or complex pattems to view. In the case of random polygons, more simple than complex figures were exposed and contrariwise in the case of stimuli taken from Berlyne's previous studies; in both cases, the differences were insignificant. Viewing times generally decreased with age, 5-year-olds, however, viewed simple figures longer than complex ones, 11-year-olds vice versa, and 8-year-olds showed no difference. The Age by Complexity interaction was discussed in terms of the dimensions of "interestingness" and "pleasingness"

In many recent studies of visual attention and exploration, preference (for complexity) has been equated with amount of fixation. In other words, those stimuli viewed longer have been regarded as preferred stimuli (e.g., Smock \& Holt, 1962; Hershenson, Munsinger, \& Kessen, 1965; Thomas, 1966). A priori there seems little justification for such an assumption. The fact that complex stimuli (i.e., those with more detail) are viewed longer than simple ones may simply mean that an individual needs to fixate or scan these stimuli more in order to identify and categorize them (Berlyne, 1958). Furthermore, recent studies have demonstrated a disjunction between the dimensions of "interestingness" and "pleasingness" (Day, 1966, 1967; Berlyne, Ogilvie, \& Parham, 1968), symmetry being more closely associated with the latter and complexity with the former.

To be satisfactory, therefore, a preference measure should involve a choice on the part of the $\mathrm{S}$-either to view a particular stimulus again or to categorize preferentially. If there is a real preference for certain stimulus attributes, then these attributes should be capable of acting as reinforcers in an operant task where one of a pair of discriminanda controlled the appearance of these stimulus characteristics.

\section{METHOD}

To test this hypothesis, a modified teaching machine (Educational Systems,
Ltd., Model 1024) was used. Each of two buttons controlled exposures of alternate frames on a $35 \cdot \mathrm{mm}$ film strip. The stimulus material consisted of five series of pairs of figures, four of which were from Berlyne (1958), representing irregularity of arrangement, amount of material, heterogeneity of elements, and irregularity of shape. There were four pairs in each of these series, one member of each pair being relatively simpler (S) than the other $(\mathrm{C})$. The fifth series consisted of randomly generated figures (Attneave \& Amoult, 1956; Munsinger \& Kessen, 1964), the $C$ members consisting of four figures each of $5,10,15$, and 20 independent turns; the $S$ members of this consisted of symmetrical 5-, 10, 15 and 20-tum figures. The patterns were produced by fitting black paper cutouts to an outline on white card. These patterns were then photographed onto $35-\mathrm{mm}$ film, the 32 pattems from Berlyne's material on the first 32 frames in a randomized sequence, with the single constraint that the $S$ members occupied odd-numbered frames and the $C$ members occupied the even-numbered ones. These 32 patterns were photographed in reverse order on the next 32 frames. Similarly, Frames 65 to 96 contained the 32 random polygon patterns whose reverse order occupied Frames 97 to 128. If the two response buttons were pressed in strict alternation, simple and complex members of successive pairs were exposed alternately; if the same button was pressed repeatedly, the simple or complex members (as the case might be) of successive pairs were exposed.

\section{SUBJECTS}

The Ss were 24 5-, 8-, and 11-year-old children, eight in each age group, with equal numbers of boys and girls.

The Ss were told that they could play with a new machine and see different pictures by pressing the buttons; they could look at each picture for as long as they wished and had to press one of the buttons when they wanted to see a new one. Six trial frames at the beginning of the film helped the Ss to get used to operating the machine. PROCEDURE

The 64 pictures were presented in four runs: (1) on Run 1 only the first 32 were available, the left button (LB) controlling the $\mathrm{S}$ pictures and the $\mathrm{RB}$ controlling the $\mathrm{C}$ 
(nnes: (2) Run 2. utilizing reverse order of Run 1, now had the $S$ pictures exposed by operation of the RB; (3) Run 3 consisted of the 32 polygons, with the LB exposing $S$; (4) Run 4 had the polygon series reversed, with RB controlling $\mathrm{S}$. There was a 5 -min break before Runs 1 and 2 and between Runs 3 and 4 , and at least $2 \mathrm{~h}$ between Runs 2 and 3 . The buttons were identified as discriminanda by use of blue and red caps. The caps were changed in position between runs, so that for any $S$ the same discriminanda always controlled the same kind of picture-blue controlled $S$ for half the Ss and red controlled for the other half. Left and right button-presses were recorded by deflections of differing amplitude on a paper write-out, and distances between subsequent presses were converted into seconds. The experiment, consisting of all four nuns, was repeated on 3 consecutive days.

\section{RESULTS}

If there was a general preference for complexity, it would be expected to selectively strengthen those responses upon which it was contingent. In other words, the number of $\mathrm{C}$ pictures exposed would be expected to progressively exceed the number of $S$ pictures on successive repetitions. In fact, analysis of variance showed no significant main effect due to repetitions. For within-series and between-series comparisons, Runs 1 and 2 were combined, as we re Runs 3 and 4, since essentially different kinds of stimuli were used in the first and second halves of the experiment. In Runs 1 and 2, mean number of responses for simple pictures was 14.8 , and for complex, 17.2; similarly, in Runs 3 and 4 , the scores were: simple, 16.8; complex, 15.2. T tests showed these differences to fall short of significance. Furthermore, no age differences were detectable in this response measure.

Nevertheless, there was a difference in mean viewing times for the two sets of pictures in the three age groups (Fig. 1). In general, viewing times decreased with age, but the striking feature was the difference between the younger and the older children-the former viewing simple pictures longer than complex ones, and the lat ter vice versa. The differences were significant at 5 years and at 11 years (standard error of means was 0.34 and 0.47 , respectively). Thus, a preference-for-complexity factor failed to manifest itself in selective reinforcement of operant responses, even when this "preference" was reflected in another response parameter. This raised the question of whether the $S s$ were aware that there were two qualitatively different sets of pictures, each controlled by a different rcsponse button. The Ss were all asked at the end of the experiment whether they had liked the pictures, whether all pictures had

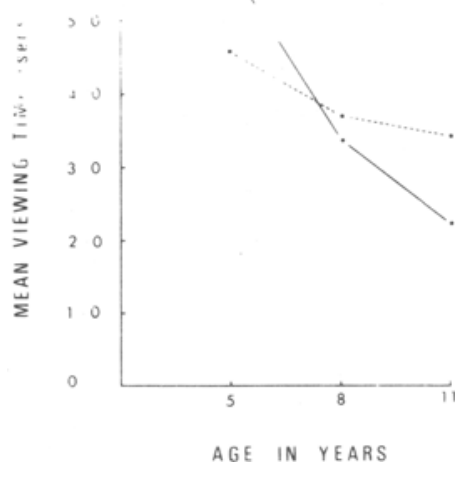

Fig. 1. Viewing times of simple and complex figures in children of different ages.

been of the same kind, and whether there was any difference between the two buttons aside from their colors. All Ss in the 11 -year group, seven Ss in the 8-year group, and three Ss in the 5-year group were aware that the two buttons brought on two different sorts of pictures, although not all were able to specify the differences.

\section{DISCUSSION}

These results raise the question as to whether equation of longer viewing time with preference is legitimate. Clearly, viewing times indicated some selective response in the older and younger children, but not in the 8-year-olds. The response strategy of the 5-year-olds proceeded in three stages: (1) operation of the buttons for the auditory and tactile feedback - no attention paid to the screen; (2) operation of the buttons merely to effect a stimulus change-still relatively little attention paid to the nature of the picture exposed; (3) attention to the kind of picture exposed and particular interest shown in those patterns that could be identified or approximated and given a verbal tag-hence, the higher scores for the simple pictures.

The lack of a discriminant performance cannot be due to an inability to discriminate between the two kinds of contingent patterns, since the majority of Ss were in fact able to do so. Nevertheless, stimulus complexity does not seem to be a variable critical in eliciting visual attention until the age of 11 years. These results are largely in agreement with others who have found "preference" for relatively simple, symmetrical, and common designs (Hoats, Miller, \& Spitz, 1963; Clapp \& Eichorn, 1965; Eisenman, 1967). In view of the independence of the judged "interestingness" and "pleasingness" of these patterns, it may well be that young children, due to their limited experience, are unable to make cualuations of interestingness and respond largely on the basis of the pleasingness of visual figures. With increasing age and experience, interestingness becomes the dimension that prevails in maintaining attention. Considering the multidimensionality of complexity (Rump, 1968; Hutt, 1969), ? it may be misleuding to use a concept like "preference-for-complexity," and certainly viewing-time would be a very poor indicator of it in young children.

\section{REFERENCES}

ATTNEAVE, F, \& ARNOULT, M. D. The quantitative study of shape and pattem perception. Psychological Bulletin, 1956, 53, 452-471.

BERLYNE, D.E. The influence of complexity and novelty in visual figures on orienting responses. Journal of Experimental Psychology, 1958, 55, 289-296.

BERLYNE, D. E., OGILVIE, J.C., \& PARHAM L. C. C. The dimensionality of visual complexity, interestingness, and pleasingness. Canadian Journal of Psychology. 1968, 22, 376-387.

CLAPP, W. 'F., \& EICHORN, D. H. Some determinants of perceptual investigatory response in children. Journal of Experimental Child Psy chology, 1965, 2, 371-388.

DAY, $H$. Looking time as a function of stimulus variables and individual differences. Perceptual \& Motor Skills, 1966, 22, 423-428.

DAY, H. Evaluations of subjective complexity, pleasingness and interestingness for a series of random polygons varying in complexity. Perception \& Psychophysics, 1967, 2, 281-286.

EISENMAN, R. Complexity-simplicity: I. Preference for symmetry and rejection of complexity. Psychonomic Science, 1967, 8, 169-170.

HERSHENSON, M- MUNSINGER, H., \& KESSEN, W. Preference for shapes of in termediate variability in the newborn human. Science, 1965, 147.630-631.

HOATS, D. L., MILLER, M. B., \& SPITZ, H. H. Experiments on perceptual curiosity in mental retardates and normals. American Journal of Mental Deficiency, 1963,68, 386-395.

HUTT, C. Complexity, curiosity and development. Proceedings of the XIXth International Congress of Psychology, London, 1969.

MUNSINGER, H., \& KESSLN, W. Uncertainty, structure and preference. Psychological Monograph, 1964, 78, 586-610.

RUMP, E. E. Is there a general factor of preference for complexity? Perception \& Psychophysics, $1968,3,346-348$.

SMOCK, C. D., \& HOLT, B. G. Children's reactions to novelty: An experimental study of "curiosity motivation." Child Development, 1962, 33 , $631-642$.

THOM AS, H. Preferences for random shapes: Ages six through ninetcen years. Child Development, $1966,37,843-859$.

\section{NOTES}

1. The authors are now in the Departments of Psychology at the University of Reading and the University of Fdinburgh, respectively. The Nufficld Foundation most generously supported this research.

2. C. Hull and P. 1. Mexirew, manustripl in preparation. 